\title{
OS CENTROS EDUCATIVOS FAMILIARES DE FORMAÇÃO EM ALTERNÂNCIA NAS REFLEXÕES SOBRE DESENVOLVIMENTO: O ESTADO DA ARTE DA PRODUÇÃO ACADÊMICA BRASILEIRA
}

\author{
Wagner da Silva ${ }^{1}$ \\ Cicilian Luiza Löwen Sahr ${ }^{2}$
}

Resumo: A Pedagogia da Alternância surgiu na França no início do século XX como uma resposta à necessidade dos jovens agricultores estudarem e auxiliarem seus pais ao mesmo tempo. No Brasil, a implantação de Centros Educativos Familiares de Formação em Alternância (CEFFA) ocorreu a partir da década de 1960. Analisa-se aqui a produção científica acerca da aplicação da Pedagogia da Alternância em instituições brasileiras. Foram realizadas buscas na Biblioteca Digital Brasileira de Teses e Dissertações para o período de 1977-2014. O foco maior de análise foi a produção que alia a Pedagogia da Alternância à discussão de Desenvolvimento rural e local/regional. Observou-se a tendência recente desta produção se desenvolver a partir de Programas de Pós-Graduação de Universidades Regionais.

Palavras-chave: Educação no Campo; Pedagogia da Alternância; Desenvolvimento; Estado da Arte

\section{THE FAMILY CENTERS OF FORMATION IN ALTERNATION ON REFLECTIONS ON DEVELOPMENT: THE STATE OF THE ART OF BRAZILIAN ACADEMIC PRODUCTION}

\begin{abstract}
The Pedagogy of Alternation emerged in France in the early 1900s as a response to the fact that young farmers simultaneously study and work in a family context. In Brazil, the establishment of the CEFFA (Centros Educativos Familiares de Formação em Alternância = Family Centers of Formation in Alternation) started in the 1960s. This research review investigates the application of the Pedagogy of Alternation in Brazilian institutions and refers to publications in the Brazilian Digital Library of Thesis and Dissertations from 1977 to 2014. The major focus of the analysis is on the relation between the Pedagogy of Alternation and rural and local/regional development. It observes the recent trend that this type of production mainly appears in Post-graduation Programs of Regional Universities.
\end{abstract}

Keywords: Rural Education; Pedagogy of Alternation; Development; State of the Art.

\section{LOS CENTROS EDUCATIVOS FAMILIARES DE FORMACIÓN EN ALTERNANCIA EN LAS REFLEXIONES SOBRE DESARROLLO: LO ESTADO DEL ARTE DE LA PRODUCCIÓN ACADEMICA BRASILEÑA}

\footnotetext{
${ }^{1}$ Wagner da Silva. Mestre em Geografia pela Universidade Estadual de Ponta Grossa (UEPG).

E-mail de contato: geo.wagner92@yahoo.com.br

${ }^{2}$ Cicilian Luiza Löwen Sahr. Docente do Programa de Pós-Graduação em Geografia da Universidade Estadual de Ponta Grossa (UEPG). E-mail de contato: cicilian@uol.com.br
} 
Resumen: La Pedagogía de la Alternancia surgió en el suroeste de Francia a principios del siglo XX como respuesta a la necesidad de los jóvenes agricultores para estudiar y al mismo tiempo ayudar a sus padres. En Brasil, la creación de Centros Educativos Familiares de Formación en Alternancia (CEFFA) surgieron en la década de 1960. Este artículo pretende analizar la producción científica que refiere la aplicación de la Pedagogía de la Alternancia en instituciones brasileñas. Para ello, se realizó la búsqueda en la Biblioteca Digital Brasileña de Tesis y Disertaciones del periodo 1977-2014. El punto clave en el análisis fue la producción científica que vincula la Pedagogía de la Alternancia con la discusión de Desarrollo rural y local / regional. Se observó la reciente tendencia de esta producción desarrollarse a partir de programas de Doctorado/Maestria en Universidades Regionales.

Palabras clave: Educación en el Campo; Pedagogía de la Alternancia; Desarrollo; Estado del Arte

\section{Introdução}

A Pedagogia da Alternância é um modelo de educação que, segundo Almada (2005, p.52), permite ao aluno alternar intervalos de tempo entre as atividades escolares e seus afazeres práticos, como o auxílio no trabalho agrícola dentro da propriedade de sua família. Levando em consideração que no espaço rural o ingresso no trabalho acontece mais cedo do que no espaço urbano, torna-se de fundamental importância o desenvolvimento de uma metodologia que consiga conciliar estudo e trabalho, sem causar prejuízos a nenhuma das duas instâncias. Busca-se com esta pedagogia amenizar a evasão do espaço rural, criando maior oportunidade para o jovem estudante e agricultor familiar desenvolver seu trabalho em sua propriedade, embasado pelos ensinamentos técnicos repassados por uma instituição de educação voltada para suas necessidades. Trata-se dos Centros Educativos Familiares de Formação em Alternância (CEFFA), como é conhecida a Casa Familiar Rural (CFR) e a Escola Família Agrícola (EFA).

O presente artigo intenta analisar a produção científica da pós-graduação stricto sensu brasileira sobre a Pedagogia da Alternância, a CFR e a EFA. A problemática na qual se assenta a referida discussão é a relação existente entre os centros produtores de conhecimento e as instituições de educação básica e técnica que se utilizam dessa pedagogia. Parte-se deste ponto, para avaliar se as pesquisas realizadas na academia estão interconectadas as práticas das CFRs e EFAs no Brasil.

A discussão tem como objetivo central analisar a produção científica, através da busca de dissertações e teses produzidas acerca da Pedagogia da Alternância no período de 1977 2014 nos Programas de Pós-Graduação (PPG) Stricto Sensu do Brasil. Dá-se continuidade e faz-se relações com as informações obtidas pelo levantamento realizado por Teixeira, Bernartt e Trindade (2008), que levou em consideração o recorte temporal 1977-2006. Esses autores, 
ao realizarem suas análises, concluíram que apesar de expressiva em termos numéricos, a Pedagogia da Alternância ainda carecia de maior ênfase e discussão por parte da comunidade científica brasileira.

A operacionalização do levantamento mais recente, complementar ao primeiro realizado, se deu através da busca na Biblioteca Digital Brasileira de Teses e Dissertações (BDTD, 2015). Os termos que basearam a procura foram: Pedagogia da Alternância, Casa Familiar Rural, Escola Família Agrícola e Educação do Campo. Estabeleceram-se ainda categorias recorrentes nestes estudos, também identificadas por Teixeira, Bernartt e Trindade (2008), pois se verificou que os trabalhos estavam ligados à Educação, ao Desenvolvimento, ao processo de implantação no Brasil e a relação família-escola.

A estrutura textual do artigo divide-se em três parcelas de discussões. Num primeiro momento é realizado um levantamento histórico acerca da difusão da Pedagogia da Alternância, de sua origem na França a sua implementação no Brasil. Num segundo momento evidenciam-se as discussões presentes na produção dos programas de mestrado e doutorado do Brasil que se relacionam à questão investigada. No terceiro momento, analisam-se as principais linhas temáticas que a abordam, explorando de forma mais efetiva, os trabalhos relacionados ao Desenvolvimento.

\section{Da Maison Familiale Rurale ao Centro Educativo Familiar de Formação em Alternância: uma trajetória}

A Pedagogia da Alternância surgiu no sudoeste da França, no período entre as duas grandes guerras do século XX, através da Maison Familiale Rurale (MFR). O desenvolvimento dessa metodologia foi uma resposta à necessidade dos jovens agricultores estudarem e ao mesmo tempo, auxiliarem seus pais. Com a participação de agricultores familiares, de líderes sindicais e da igreja católica, surgiu a primeira instituição que aliou no processo de formação a teoria e a prática. Portanto, em sua gênese, ela possuía um viés mais voltado ao atendimento das necessidades econômicas da região do que a demanda por uma educação rural (ESTEVAM, 2003, p.34). Isso reforça a necessidade de aprofundamento das reflexões sobre a articulação entre esta Pedagogia e o Desenvolvimento rural e/ou local/regional.

Depois de seu surgimento em território francês, o primeiro país a receber uma MFR foi a Itália, que em 1958 implantou uma instituição na região de Verona. Segundo Nosella (2012, p.56), dentro do território italiano as MFRs sofreram algumas modificações, dentre as 
mais importantes a nomenclatura, passando a se chamar Scuole Della Famiglia Rurale. Entre as mudanças metodológicas, destaca-se a do período de alternância que era de 7 dias na experiência francesa e de 15 dias na experiência italiana.

Gradativamente essas instituições ultrapassaram as fronteiras europeias, chegando em diversos pontos do planeta, com a mesma operacionalidade, se integrando ou não nas diferentes realidades. Segundo a Associação Internacional dos Movimentos Familiares de Formação Rural (AIMFR, 2015), a Pedagogia da Alternância, depois de sua origem na Europa, teve uma expansão considerável. Hoje ela está presente nos cinco continentes do planeta.

Analisando os países que praticam a alternância, a AIMFR (2015) percebeu que com exceção do Canadá e de alguns países da Europa, como França e Bélgica, o restante dos países que abrigam os CEFFAS pode ser classificado em dois grupos. Trata-se do grupo com economias em desenvolvimento e do grupo daqueles que apresentam um atraso econômico em relação às grandes potências mundiais. Desta forma, ressalta-se mais uma vez a operacionalidade da Pedagogia da Alternância como ferramenta de auxílio à população rural que mais carece de elaboração de políticas públicas e atenção governamental, bem como, da articulação desta pedagogia com a busca em propiciar o Desenvolvimento rural e/ou local/regional.

No Brasil, a implantação dos CEFFAs aconteceu em dois momentos, o que resultou em dois formatos distintos de instituições independentes. Segundo Estevam (2003, p.55), em 1968, sob influência dos imigrantes italianos, instalou-se no estado do Espírito Santo a primeira EFA do país. Já na década de 1980, sob influência francesa, houve a tentativa de se instalar duas CFRs na região nordeste do Brasil. Porém essas experiências tiveram uma curta duração (ESTEVAM, 2003, p.57).

Não obstante, essa tentativa de implantação no nordeste brasileiro não foi sem importância, uma vez que elas basearam a instalação exitosa destas instituições no sul do Brasil. Em 1987, segundo a Secretaria de Educação do Estado do Paraná (2015), foram implantadas uma escola no município de Barracão e outra em Santo Antônio do Sudoeste. Portanto, o Paraná abriu caminho para que os outros dois estados sulinos efetivassem a experiência da alternância em seu território.

No Brasil os CEFFAs estão hoje presentes em todas as regiões (Figura 01), constituindo um aporte aos jovens agricultores familiares que necessitam de um estudo de qualidade e, ao mesmo tempo, conciliar seus afazeres laborais. Os centros brasileiros estão 
subdivididos principalmente em Casas Familiares Rurais (CFRs) influenciadas pelas práticas francesas e Escolas Famílias Agrícolas (EFAs) influenciadas pelas experiências italianas.

Figura 01 - Distribuição dos Centros Educativos Familiares de Formação em Alternância (CEFFAS) no Brasil - 2015

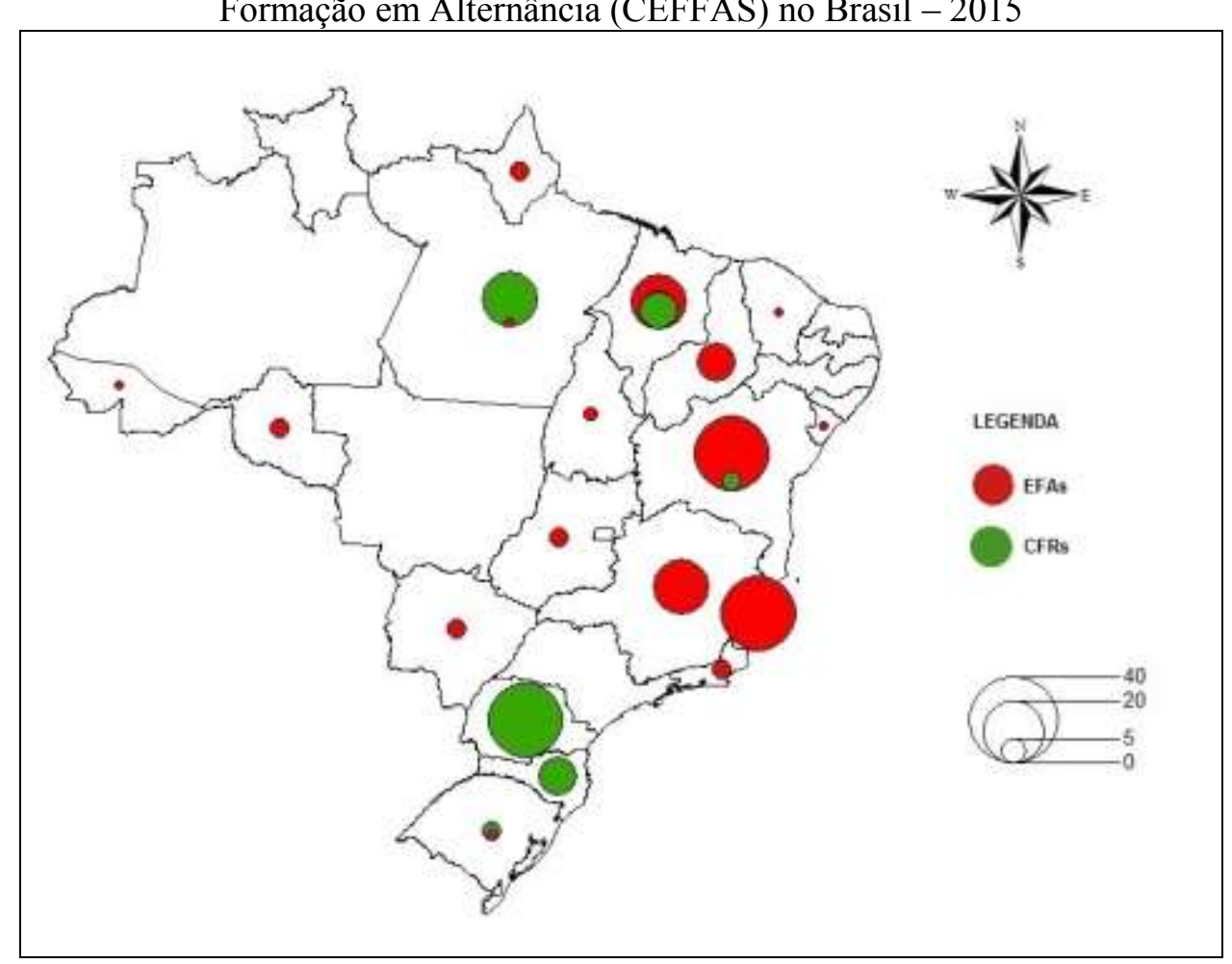

Nota: EFA - Escola Familiar Agrícola e CRF - Casa Familiar Rural Fonte: UNEFAB (2015) e ARCAFARs (2015)

Org.: SILVA, LÖWEN SAHR e GOMES (2015)

Segundo Estevam (2003, p.56), além da nomenclatura, as EFAs se diferenciam das CFRs através do período de alternância no ensino médio e entidades de coordenação. No ensino médio, as EFAs adotam o sistema de alternância italiano de 15 dias e no fundamental, o intervalo de alternância francês de 7 dias. No âmbito administrativo, as EFAs são coordenadas pela União Nacional das Escolas Famílias Agrícolas do Brasil (UNEFAB) e as CFRs do sul do Brasil são administradas pela Associação Regional das Casas Familiares Rurais do Sul do Brasil (ARCAFAR/SUL). Na região norte e nordeste, as CFRs existentes nos estados do Pará, Amazonas, Bahia e Maranhão são organizadas pela ARCAFAR NORTE/NORDESTE.

Pode-se então perceber que os CEFFAS brasileiros estão distribuídos pelas cinco regiões do país, com maior concentração no nordeste. Dessa forma, concorda-se com Begnami quando afirma que: 
Constata-se que a maioria dos CEFFAs está localizada em regiões menos desenvolvidas, com mais pessoas e jovens no campo, com uma participação maior da agricultura na composição da economia local e em municípios menores, tanto em termos populacionais assim como econômicos. (BEGNAMI, 2013, p.8)

Trata-se da escolha prioritária de regiões interioranas, municípios de pequeno e médio porte, nos quais as atividades agrícolas familiares exercem uma influência socioeconômica importante. Desde o seu surgimento até a chegada ao Brasil, a Pedagogia da Alternância manteve essas características. Foi pensada como potencial alternativo na resolução de crises econômicas. Vista na França como uma possibilidade de propiciar que jovens agricultores desfrutassem de uma melhor qualidade de vida em período de dificuldades econômicas, atualmente no Brasil, segue com esse mesmo pensamento e se volta ao público rural que mais carece de políticas públicas: os agricultores familiares.

Torna-se importante ressaltar que os CEFFAS não são iniciativas elaboradas pelo poder público, mas sim de grupos de pessoas - como agricultores familiares, sindicalistas e comunidade interessada - que buscam parcerias com os governos municipal, estadual e federal, além de subsídios e auxílios com empresas públicas e privadas. Dessa forma, percebe-se que a dinâmica parte de quem necessita e não de quem planeja o sistema educativo brasileiro.

\section{O estado da arte e as reflexões acadêmicas sobre os CEFFAS}

O levantamento das dissertações e teses sobre a Pedagogia da Alternância defendidas entre os anos de 1977 e 2006 no Brasil foi realizado por Teixeira, Bernartt e Trindade (2008). Dando continuidade e complementaridade a tal levantamento, realizaram-se buscas sobre os trabalhos defendidos entre os anos de 2007 e 2014. Estes dois levantamentos compõem a base de dados (86 teses e dissertações) que embasa as análises e conclusões propostas neste artigo. Destaca-se que o cruzamento entre as informações torna-se importante para compreender a dinâmica das discussões acadêmicas ao longo do tempo (Figura 02).

Figura 02 - Crescimento do número de Teses e Dissertações sobre Pedagogia de Alternância entre 1977 e 2014 


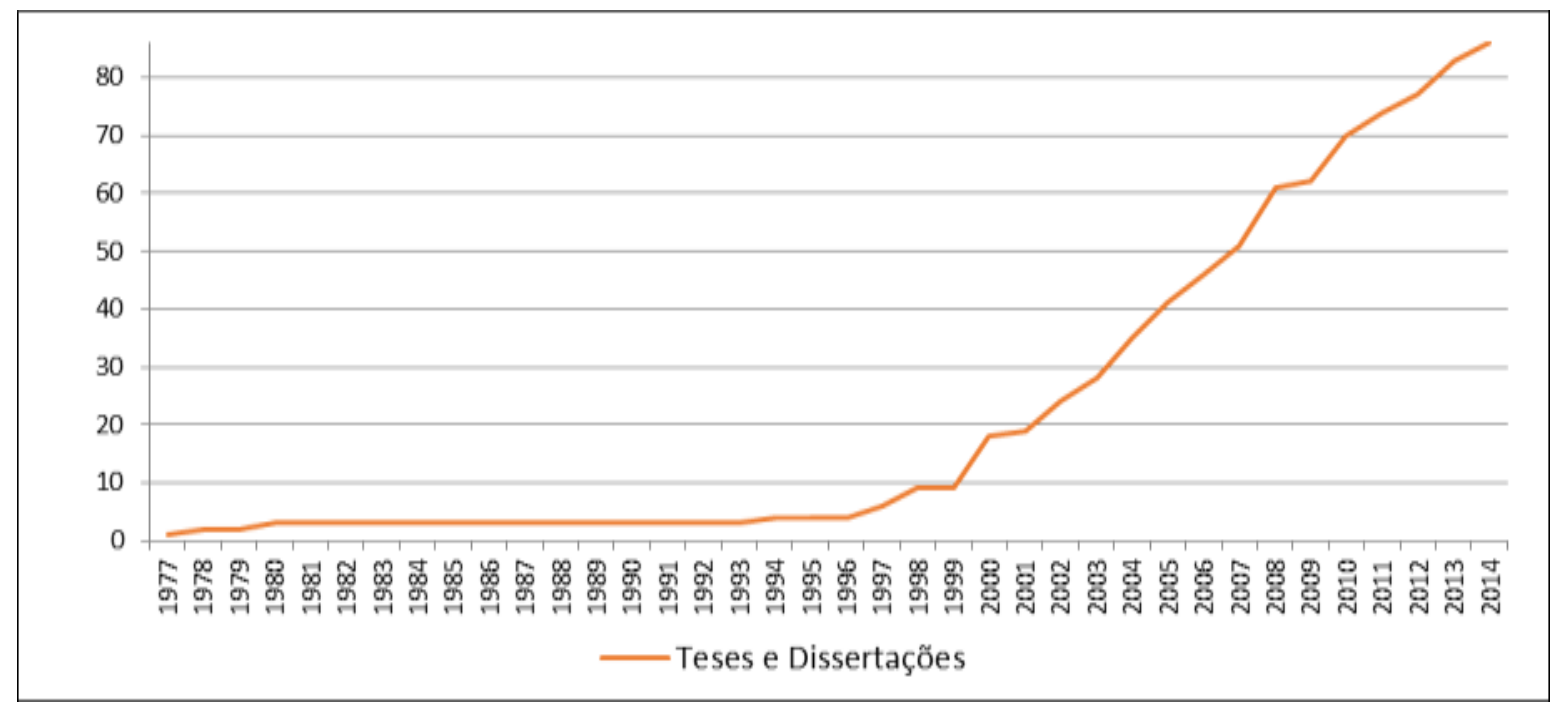

Fontes: 1977-2006 (TEIXEIRA, BERNARTT e TRINDADE, 2008) e 2007-2014 (BDTD, 2015). Org.: SILVA e LÖWEN SAHR (2015).

Observa-se que entre a primeira dissertação defendida e o final dos anos 1990, a temática da Pedagogia da Alternância não esteve muito presente no debate acadêmico. É a partir de 1998 que se verifica um crescimento gradativo e contínuo do número de teses e dissertações ao longo do período analisado. A análise da dinâmica temporal possibilita ainda estabelecer alguns prognósticos acerca da temática.

Teixeira, Bernartt e Trindade (2008) quando realizaram o levantamento até 2006, perceberam que a primeira discussão acadêmica sobre o tema tardou a ser efetivada. A Pedagogia da Alternância se fixou no Brasil em 1969, mas o primeiro trabalho foi defendido apenas no ano de 1977, estabelecendo uma lacuna acadêmica de 8 anos. Estes autores também concluíram que o número de teses e dissertações, apesar de considerado expressivo, era disperso considerando o intervalo de tempo analisado. Em 29 anos foram apresentados de forma esparsa e intercalada 46 trabalhos (p.230).

Observando a distribuição temporal entre 1977 e 2006 e fazendo uma média, tem-se 1,6 teses/dissertações defendidas por ano. A realidade para o período mais abrangente, ou seja, de 1977 a 2014, entretanto, é diferente, com uma média de 2,3 teses/dissertações ao ano, o que representa um incremento significativo nos últimos 7 anos. A década de 1970 marca o início das reflexões acadêmicas sobre Pedagogia da Alternância. No período de 1981-1990, todavia, se assiste a ausência de trabalhos referentes ao tema. Durante o decorrer da década de 1990, 6 dissertações e 1 tese foram defendidas. A primeira década do século XXI é a fase auge, que tem continuidade nesta segunda década. Acredita-se que a falta de constância acomete os mais variados temas, existindo períodos que as discussões se acaloram e outros em que estas se aquietam. 
Até os anos 2000 a produção caminhava a passo mais lentos, a partir daí há um crescimento extraordinário. De 18 defesas ocorridas até o fim do século XX, passa-se para o total de 86 até 2014. De 2000 a 2010 houve a defesa de 52 trabalhos, e nos últimos quatro anos de análise foram defendidos 16 . Se continuar o mesmo ritmo, a presente década fechará com 40 defesas acerca do tema. Percebe-se assim uma tendência de desaceleração no ritmo de produção das teses e dissertações sobre a Pedagogia da Alternância na atualidade.

Quanto à distribuição espacial, há uma tendência inicial de concentração da produção nas regiões Sudeste, Sul e Centro-Oeste (Figura 03). Há ocorrência de trabalhos acadêmicos nestas regiões em todas as décadas analisadas. Nas regiões Norte e Nordeste só foram encontradas teses e dissertações sobre a temática a partir de 2000. A região Sul se destaca no cenário nacional pela concentração mais acentuada nos quatro últimos anos analisados, indicando uma tendência recente. 
Figura 03 - Distribuição regional das teses e dissertações sobre Pedagogia de Alternância entre 1977 e 2014

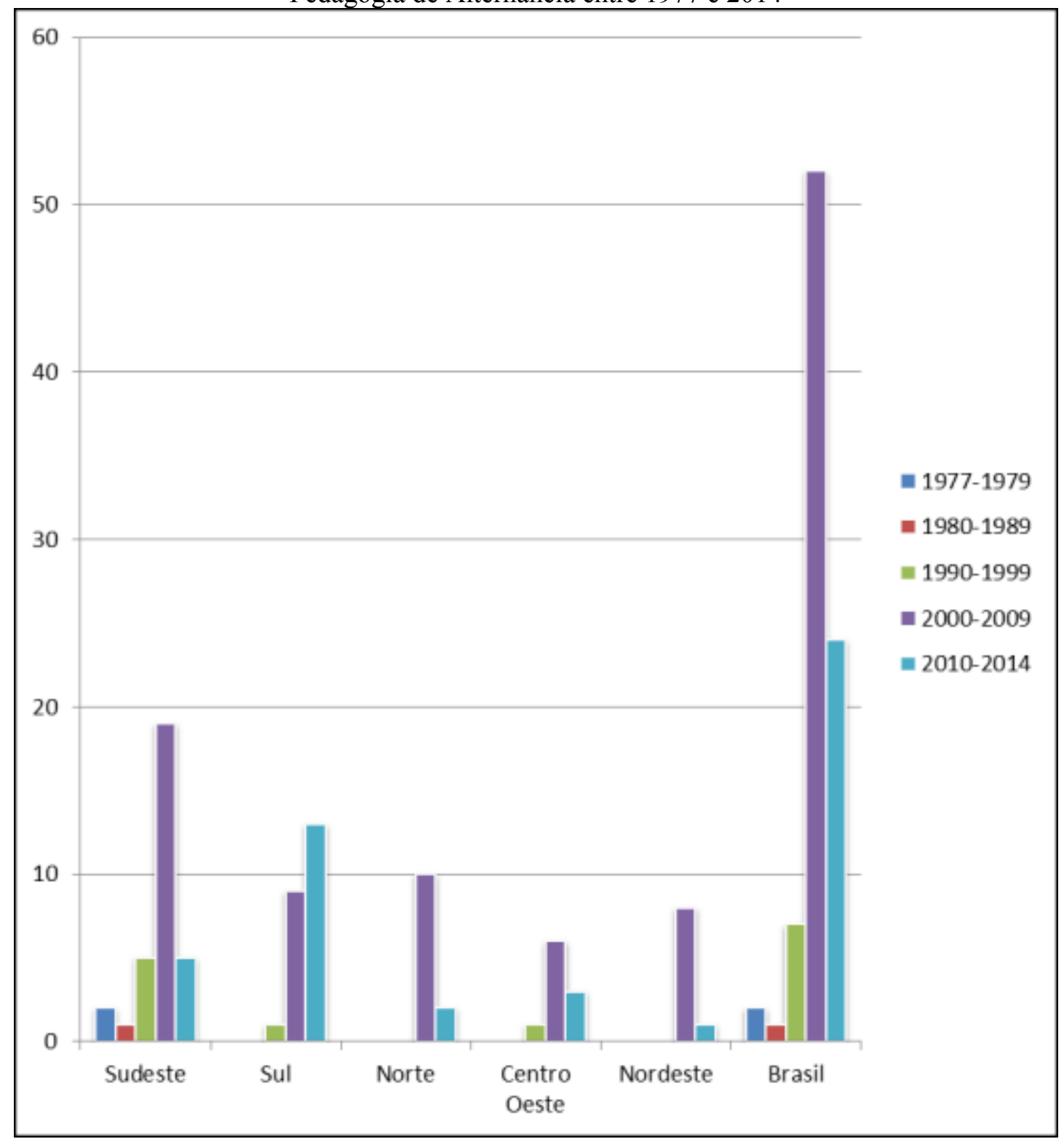

Fontes: 1977-2006 (TEIXEIRA, BERNARTT e TRINDADE, 2008) e 2007-2014 (BDTD, 2015). Org.: SILVA, LÖWEN SAHR e BUENO (2015).

Considerando ainda as cinco regiões brasileiras, pode ser feita uma análise da relação entre a distribuição dos CEFFAS e da discussão científica em torno do tema (Figura 04). Com isso pode-se esclarecer até que ponto as reflexões tem um caráter regional, ou seja, se elas refletem estudos sobre os Centros localizados na área de influência das instituições produtoras de conhecimento.

Figura 04 - Distribuição dos Programas de Pós-Graduação e das Teses e Dissertações sobre Pedagogia de Alternância no Brasil de 1977 a 2014 


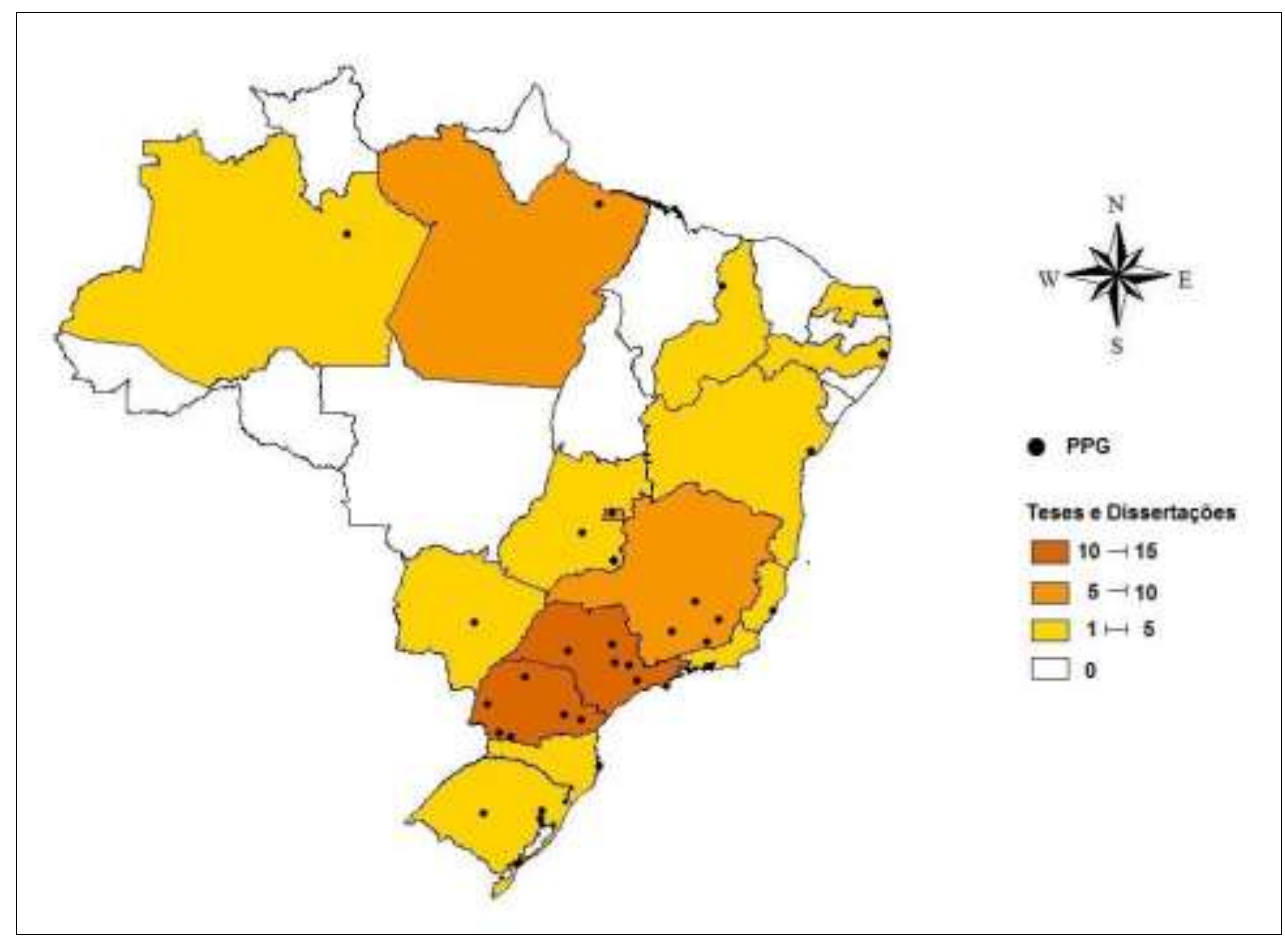

Fontes: 1977-2006 (TEIXEIRA, BERNARTT e TRINDADE, 2008) e 2007-2014 (BDTD, 2015)

Org.: SILVA, LÖWEN SAHR e GOMES (2015)

Na integração dos dois momentos de busca (1977-2006 e 2007-2014), com 32 trabalhos, o Sudeste lidera a produção de teses e dissertações acerca da Pedagogia da Alternância desde os primórdios. Uma análise mais específica, sobre a relação do número de CEFFAS comparada com os trabalhos produzidos, aponta que o Sudeste foi responsável por $37,2 \%$ dos trabalhos desenvolvidos até a atualidade, sendo que esta região possui $18,6 \%$ dos Centros do Brasil. Portanto, nota-se um suposto descompasso entre a localização dos Centros e a localização das reflexões teóricas, o que não pode ser desmitificado sem analisarmos a origem dos autores das teses e dissertações ${ }^{3}$. Em virtude dos Programas de Pós-Graduação (PPG) se concentrar no Sudeste, estes acabam por polarizar pesquisadores das diversas regiões do país, que muitas vezes desenvolvem suas pesquisas sobre temas correlatos a sua região de origem.

Dentre as regiões brasileiras, Teixeira, Bernartt e Trindade (2008, p.231) apontam para o período de 1977 a 2006 a participação numerosa de trabalhos defendidos no Sudeste, sobretudo nos estados de São Paulo e Minas Gerais. Justificando o fato, considera-se que nessa região se concentram as principais universidades brasileiras. Há que se lembrar, que por muito tempo os PPG eram desenvolvidos apenas nos grandes centros e capitais. O deslocamento destes para o interior é um fenômeno mais recente.

\footnotetext{
${ }^{3}$ Este levantamento é possível, entretanto, deixaremos de lado neste momento.
} 
No segundo levantamento, de 2007 a 2014, o Sudeste é acompanhado de perto pela região Sul. Esta região foi responsável por 25 defesas entre teses e dissertações, diminuindo bastante sua distância em relação à região Sudeste, que é a que mais discutiu o tema nos dois períodos analisados. Alguns argumentos justificam tal situação, destacando-se, como exemplos, o empenho dos PPG e pesquisadores da UTFPR de Pato Branco e da UFSC em disseminar discussões sobre o regime de alternância. Comparando a relação entre defesas de teses e dissertações e CEFFAS da região, obtém-se 29,06\% das produções científicas e 25,6\% dos centros de formação, estreitando a diferença, de forma a aproximar-se do equilíbrio.

A região Norte conta com 17,5\% dos CEFFAS do Brasil, sendo um total de 45 instituições. No quesito trabalhos defendidos no período total, ela foi sede de 11,6\%, demonstrando equilíbrio, porém, com índices abaixo da média de outras regiões. O Centro Oeste possui apenas 2,3\% dos CEFFAS do país, em contrapartida apresentou 12,8\%, das discussões aqui analisadas, destaque a produção acadêmica da UFG, UNB e UCB.

O Nordeste, todavia, é a região brasileira que apresenta o menor número de defesas de teses e dissertações sobre Pedagogia da Alternância, com apenas oito trabalhos ou 9,3\%, todos eles defendidos a partir dos anos 2000. Por contraste, é a que mais contém CEFFAS no país $-36 \%$ do total.

Ainda caracterizando as discussões acadêmicas, neste momento torna-se importante observar quais são as principais instituições de ensino superior (IES) do Brasil que estão discutindo a Pedagogia da Alternância e os diversos horizontes de abordagem. Essa análise auxilia na compreensão dos aspectos geográficos para além da caracterização das regiões brasileiras (que também é importante) em que estão ocorrendo os estudos. Acrescenta-se ainda a relevância de analisar a concentração dos trabalhos nas capitais e a dispersão para os municípios do interior, uma vez destacada a operacionalidade e encaixe geográfico da Pedagogia da Alternância.

Dessa forma, no que diz respeito à distribuição das instituições de ensino superior, Teixeira, Bernartt e Trindade (2008, p.231) destacaram a PUC-SP como IES que mais sediou discussões sobre o tema no período 1977-2006, com uma tese e três dissertações. Curiosamente, no levantamento realizado no período 2007-2014, não foi encontrado nenhum trabalho da referida instituição sobre a temática.

Quando se observa o período todo, percebe-se também que nos últimos sete anos as discussões se descentralizaram. É visível que o tema foi ganhando uma abrangência cada vez maior no cenário brasileiro, alcançando as mais variadas instituições de ensino, de caráter 
público e privada, além de se pulverizar em diferentes contextos acadêmicos. O número de teses de doutorado (15), apesar de permanecer expressivo, ainda é bem inferior ao de dissertações de mestrado (71), o que reflete a tendência geral, já que há muito mais conclusões de mestrado do que de doutorado.

A instituição que mais se destaca na análise integral dos dados (1977-2014), é a UFPA, com oito dissertações, mantendo constante a produção nos últimos anos, uma vez que no levantamento anterior já contava com três trabalhos defendidos. Essa dialética de dados permite afirmar que houve um aumento no número de IES que discutem a temática, pois entre 1977 e 2006, 28 instituições eram responsáveis por todas as defesas, atualizando o levantamento para 2014, constatou-se 43 instituições que contribuem para a expansão dessa discussão.

O Espírito Santo foi o primeiro estado brasileiro a sediar uma instituição de ensino com o método da Pedagogia da Alternância. Ele é responsável por quatro dissertações e uma tese, contudo, todos os trabalhos estão concentrados na capital Vitória. As 25 EFAS existentes no estado, entretanto, se localizam no interior (UNEFAB, 2015). Detecta-se, assim, um possível desencontro entre a realidade vivenciada e as discussões teóricas ${ }^{4}$.

Salienta-se também o ingresso da UFRRJ, universidade que possui PPGs voltados especificamente para a área rural do Brasil. Essa instituição passou a integrar o rol das IES que discutem a alternância com dois trabalhos defendidos a partir de 2008.

Pode-se observar ainda um crescimento das discussões nas IES do estado do Paraná, destacando-se a UTFPR de Pato Branco com seis dissertações de mestrado sobre a temática. Esta IES é de longe a que mais se destaca no estado atualmente, contribuindo para firmar a unidade federativa como a que mais vem discutindo o tema na pós-graduação brasileira. Notase também que no âmbito paranaense não há uma monopolização por parte da capital do estado, como ocorre na maioria das unidades federativas do Brasil. É no interior que ocorre a maior parte das defesas de trabalhos nas pós-graduações sobre Pedagogia da Alternância. Curitiba foi sede de apenas duas das 15 teses e dissertações produzidas no estado. Nesse caso, isso pode ser indício de que a academia está mais próxima da realidade, provavelmente em função de pesquisas extensionistas.

Nos outros dois estados sulinos, onde também as Casas Familiares Rurais predominam, há duas situações diferentes. No Rio Grande do Sul foram defendidas cinco dissertações e uma tese, sendo três dissertações na capital Porto Alegre e duas dissertações e

\footnotetext{
${ }^{4}$ Esta análise é possível, entretanto, deixaremos de lado neste momento.
} 
uma tese no interior. Já em Santa Catarina, a concentração é maior ainda, pois os quatro trabalhos (uma tese e três dissertações) foram defendidos na capital, mais especificamente na UFSC.

O segundo estado que mais contribui na atualidade é São Paulo, com 14 trabalhos defendidos, sendo a capital de São Paulo a responsável por oito destas defesas. A distribuição ainda está centralizada em sua maioria na capital, mas outros seis trabalhos são provenientes de cidades do interior, destaque para a UNESP de Marília, com duas teses e uma dissertação. Interessante notar que o estado não conta com nenhuma EFA ou CFR, portanto os estudos possuem objetos de investigação em outros estados.

Torna-se importante também, a análise dos PPGs do Brasil que vem se encarregando das discussões sobre a Pedagogia da Alternância. Com tal análise, se acredita ser possível observar os vieses teóricos que embasam os estudos, uma vez que o objeto possibilita a abertura de reflexões construídas de diversos pontos de partida.

A Figura 05 demonstra os resultados de levantamento realizado nos diferentes PPGs do Brasil. Pode-se apontar a grande centralização encontrada nos PPGs voltados para a área da Educação. Além disso, observa-se que esses programas foram os pioneiros nos trabalhos que se preocuparam com a Pedagogia da Alternância. Nota-se ainda, que em todos os recortes temporais presentes na análise, o viés da Educação esteve presente na maioria dos trabalhos. Tais constatações são previsíveis, já que se trata de uma pedagogia de ensino voltada para um público específico, o jovem agricultor familiar.

Figura 05 - Distribuição temporal das teses e dissertações sobre Pedagogia de Alternância, segundo a modalidade de Programa de Pós-Graduação - 1977 a 2014 


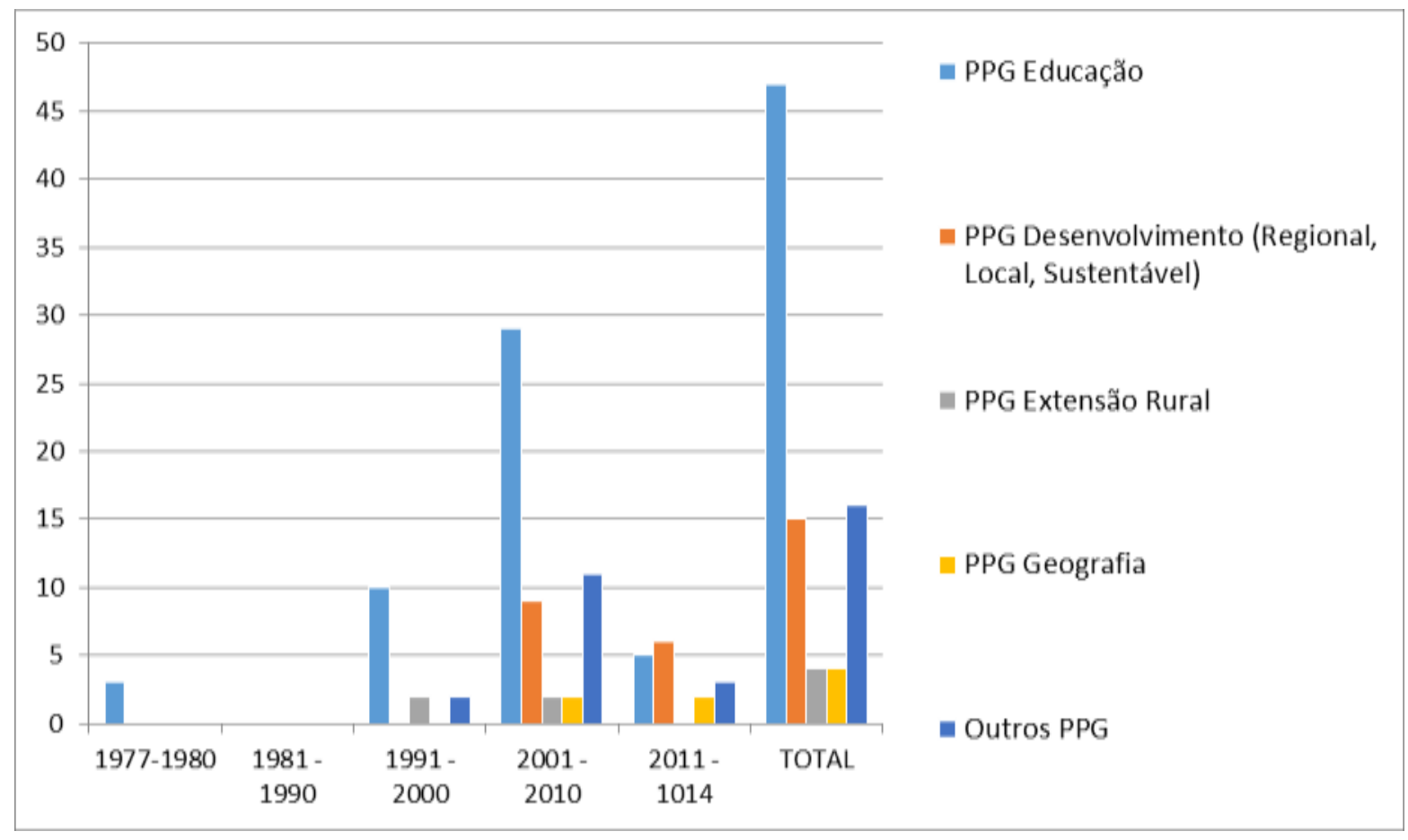

Nota: A categoria “outros" entre 2000 e 2010 se refere a Ciências Sociais (3), Administração (2), Antropologia (1), Economia (1), Sociologia (1), Ciências da Família (1), Eng. Produção (1) e Multidisciplinar (1). Para o periodo entre 2011 e 2014 se refere a Sociologia (1), Administração (1) e Tecnologia (1).

Fontes: 1977-2006 (TEIXEIRA, BERNARTT e TRINDADE, 2008) e 2007-2014 (BDTD, 2015).

Org.: SILVA e LÖWEN SAHR (2015)

Os temas ligados ao Desenvolvimento formam o segundo maior cabedal teórico das pesquisas e são recentes, uma vez que os primeiros trabalhos com essa temática surgiram no início do presente século. Tem destaque o último período (2011-2014), com um aumento considerável de trabalhos que buscam relacionar CEFFAS e Desenvolvimento. Os PPG em Extensão Rural e Geografia ganham importancia nesta análise, o de Extensão Rural por ser o terceiro maior aporte de discussões e o de Geografia porque possibilita a compreensão qualitativa da inserção dos CEFFAS no rural brasileiro, bem como a efetividade dessas instituições.

Destaca-se ainda que o fato da discussão estar inserida dentro de um PPG não "engessa" o seu tema. Um trabalho discutido com o viés da Educação, pode analisar os fatores educacionais como ferramentas para o Desenvolvimento, por exemplo. Ou então, uma análise com base epistemológica geográfica pode investigar a metodologia do ensino. Essa integração entre temas e programas torna o objeto do presente artigo um campo fértil de análise, e ao mesmo tempo, um desafio dentro do "emaranhado" de discussões.

\section{O Desenvolvimento como linha temática de discussão da Pedagogia da Alternância}


Os principais temas discutidos nas teses e dissertações sobre Pedagogia da Alternância estão centrados no quarteto Educação, Desenvolvimento, Influência Familiar e Histórico de Implantações dos CEFFAS no Brasil (Tabela 01). Dentro do primeiro levantamento realizado, Teixeira, Bernartt e Trindade (2008, p.232) já notaram a predominância de discussões baseadas nas áreas de Educação do Campo e voltadas para o Desenvolvimento em seus diversos aspectos (local, rural, etc.). Essas duas linhas compunham 60,87\% das dissertações e teses encontradas até o ano de 2006. O que se verificou na atualização das análises foi o aumento dessa concentração de trabalhos relacionados aos dois temas, sendo que de 2007 até 2014, Desenvolvimento e Educação do Campo compunham 74,40\% das discussões relacionadas à Pedagogia da Alternância.

Tabela 01 - Distribuição das teses e dissertações no Brasil sobre

Pedagogia da Alternância por linha temática - 1977 a 2014

\begin{tabular}{|l|r|r|r|}
\hline Linha temática & \multicolumn{1}{c|}{$\begin{array}{c}\text { 1977-2006 } \\
\text { (n.) }\end{array}$} & \multicolumn{1}{c|}{$\begin{array}{c}\text { 2007-2014 } \\
\text { (n.) }\end{array}$} & \multicolumn{1}{|c|}{ Total } \\
\hline Pedagogia da Alternância e Educação do Campo & 16 & 22 & 38 \\
\hline Pedagogia da Alternância e Desenvolvimento & 12 & 14 & 26 \\
\hline Processo de Implantação de CEFFAs no Brasil & 8 & 0 & 8 \\
\hline Relações entre CEFFAs e Famílias & 4 & 4 & 8 \\
\hline Outras Linhas Temáticas & 6 & 0 & 6 \\
\hline Total & $\mathbf{4 6}$ & $\mathbf{4 0}$ & $\mathbf{8 6}$ \\
\hline
\end{tabular}

Fontes: 1977-2006 (TEIXEIRA, BERNARTT e TRINDADE, 2008) e 2007-2014 (BDTD, 2015.)

Org.: SILVA (2015)

$\mathrm{Na}$ análise mais recente, a partir de 2007, destaca-se que não foram encontrados trabalhos que tratam sobre o Histórico das Implantações dos CEFFAS no Brasil. Tal tema parece ter sido exaurido na primeira fase. Em segundo plano encontram-se também as discussões sobre a Relação Instituição-Família, essas se restringem aos Programas de PósGraduação em Ciências Sociais, Desenvolvimento Regional e Educação. Já se desenhava um número reduzido de trabalhos sobre o elo Família-CEFFA no levantamento anterior, havendo uma queda maior ainda com o passar do tempo.

Alguns trabalhos foram classificados como "outros". Estes são discussões que não puderam ser integradas à subdivisão que contempla os quatro principais eixos temáticos. Existiram casos de trabalhos voltados para educação ambiental, análise etnográfica (Antropologia), menção à identidade do homem rural em relação ao urbano, etc. 
É possível perceber, na Tabela 01, que os PPG relacionados à Educação, sobretudo no Campo, fomentaram discussões acerca da Pedagogia da Alternância nas duas fases. Isso também ocorreu com relação aos trabalhos relacionados ao Desenvolvimento. O principal foco do presente artigo são estes trabalhos relacionados ao Desenvolvimento, portanto as especificações que se seguem são referentes a essa linha temática.

No primeiro levantamento foram encontrados 12 trabalhos de investigação referentes a essa linha temática, sendo os de Manhani (2000), Gnoatto (2000), Amaral (2002), Caliari (2002), Passador (2003), Sandri (2004), Chaves (2004), Rubenich (2004), Almada (2005), Araújo (2005), Nascimento (2005) e Manzoni (2005).

Teixeira, Bernartt e Trindade (2008, p.234) dividem as discussões desta primeira fase em três grupos principais - Desenvolvimento Local, Desenvolvimento Rural e Desenvolvimento Social. Destacam ainda que todas as discussões levam em consideração o protagonismo do jovem agricultor familiar como elemento constituinte de um possível processo de Desenvolvimento, esse que seria embasado pelo método da alternância proposto pelos CEFFAS.

No que se refere à atualização das análises, soma-se ao número inicial mais 14 discussões, portanto pode-se afirmar que houve um aumento no que diz respeito aos trabalhos voltados para o foco do Desenvolvimento. Entre 2007 e 2014 as discussões foram elaboradas por Palitot (2007); Fonseca (2008), Schneider (2008), Wolochen (2008); Carmo (2010), Estevam (2010), Jesus (2010), Melo (2010); Borges (2012), Bressiani (2012), Fritz (2012), Palaro (2012); Straub (2013) e Valadão (2014).

É importante salientar a pluralidade dos PPGs que associam a Pedagogia da Alternância ao Desenvolvimento na atualidade. Tem-se que 11 diferentes programas foram responsáveis pelas produções. Sete trabalhos se desenvolveram em três PPGs de Desenvolvimento Regional, um em Extensão Rural, um em Organizações e Desenvolvimento, um em Educação, um em Desenvolvimento Rural, um em Engenharia de Produção, um em Geografia, um em Políticas Públicas e outro em Administração.

No âmbito do Desenvolvimento Local tem-se: a) Palitot (2007), que fez um estudo exploratório buscando analisar a coerência entre a lógica pedagógica da Escola Rural de Massaroca-BA e as necessidades de seu público, bem como da região que ela está inserida; b) Schneider (2008), que numa pesquisa sobre os egressos do Centro de Desenvolvimento do Jovem Rural na região de Vale do Rio Pardo - RS, estudou a representação dos egressos enquanto agricultores ou empreendedores, focando na permanência do jovem no campo; c) 
Wolochen (2008), que buscou evidências de Desenvolvimento local propiciadas pela formação dos jovens agricultores na CFR de Bituruna-PR, através da Pedagogia da Alternância; d) Fonseca (2008), que através de estudo de caso, realizou uma pesquisa exploratória na EFA de Orizona-GO, investigando as contribuições dessa instituição para o Desenvolvimento sustentável local; e) Estevam (2010), que em sua tese de doutoramento, valendo-se de um estudo de caso sobre os egressos da CFR de Armazém do Sul-SC, analisou a efetividade da Pedagogia da Alternância proposta naquela instituição para o desenvolvimento local; f) Melo (2010), que investigou em sua dissertação, a colaboração do método de alternância para o Desenvolvimento local e solidário da Casa Familiar Rural de Boa Vista do Ramos-AM; g) Borges (2012), que em sua dissertação analisou como a Pedagogia da Alternância influencia no protagonismo do jovem rural em três CFRs do Sudoeste do Paraná; h) Palaro (2012), que analisou a categoria trabalho dentro da Pedagogia da Alternância desenvolvida na CFR de Manfrinópolis - PR; i) Bressiani (2012), que investigou a Pedagogia da Alternância da CFR de Dois Vizinhos-PR buscando contribuir para a gestão de famílias agricultoras com vistas à sustentabilidade; j) Straub (2013), que discutiu os processos decisórios de administração nas CFRs de Manfrinópolis e Pato BrancoPR.

Quanto ao Desenvolvimento Rural tem-se: a) Novais (2010), que na sua dissertação em Geografia, buscou as contribuições de três EFAs do estado de Goiás para o fortalecimento da agricultura camponesa; b) Carmo (2010), que analisou a relação entre qualificação do agricultor familiar e sua permanência no campo com boa qualidade de vida; c) Fritz (2012), que analisou as políticas públicas voltadas ao fortalecimento da sucessão familiar na agricultura, bem como o Desenvolvimento rural pautado pela atuação das CFRs; c) Valadão (2014), que analisou como as tecnologias sociais influenciam na técnica da alternância em Rondônia.

Quando se observa a produção acadêmica na linha de Desenvolvimento associada à da Pedagogia da Alternância, se nota a repetição de algumas ideias, tais como o protagonismo do jovem rural, sustentabilidade, sucessão familiar, agricultura familiar e efetividade do sistema de alternância. No que diz respeito à metodologia empregada, se tem a predominância de estudos de caso, seja em municípios ou regiões definidas. Assim, a grande maioria das teses e dissertações que refletem a articulação entre a Pedagogia da Alternância e o Desenvolvimento se baseia em estudos de natureza empírica, partindo das diferentes realidades que permeiam os CEFFAs. 
Para ir além da forma de abordagem do Desenvolvimento, analisa-se os principais autores que basearam as discussões dos trabalhos que trataram deste tema. Destaca-se que das 26 teses e dissertação que fazem a articulação entre Pedagogia da Alternancia e Desenvolvimento, foram encontradas apenas 20 com o texto integral disponível para leitura. Apontar um autor ou uma linha de pensamento principal, não significou que se valeu apenas daquele ponto de vista, pelo contrário, em todos os trabalhos analisados foram encontrados mais de um autor central que baseou a discussão sobre Desenvolvimento. Na Tabela 02 são destacados os autores presentes com maior densidade nas teses e dissertações analisadas. 
Tabela 02 - Principais autores que basearam as discussões das teses e dissertações que relacionam

Desenvolvimento e Pedagogia da Alternância - 1977 a 2014

\begin{tabular}{|c|c|c|}
\hline $\begin{array}{c}\text { Discussão sobre Desenvolvimento } \\
\text { (Autores) }\end{array}$ & $\begin{array}{l}\text { Frequência } \\
\text { (n.) }\end{array}$ & $\begin{array}{l}\text { Teses e Dissertações } \\
\text { (autores) }\end{array}$ \\
\hline Calvó (1999 e 2002) & 4 & $\begin{array}{l}\text { Palaro (2012), } \\
\text { Estevam (2010) } \\
\text { Fonseca (2008) } \\
\text { Araújo (2005) }\end{array}$ \\
\hline Gimonet (2007) & 3 & $\begin{array}{c}\text { Borges (2012) } \\
\text { Jesus (2010) } \\
\text { Wolochen (2008) }\end{array}$ \\
\hline Buarque (1999 e 2002) & 2 & $\begin{array}{c}\text { Melo (2010) } \\
\text { Almada (2005) }\end{array}$ \\
\hline Dagnino et. al (2010) & 1 & Valadão (2014) \\
\hline Altiere et. al (2009) & 1 & Bressiani (2012) \\
\hline Abramovay (2007) & 1 & Schneider (2008) \\
\hline Stropasolas (2006) & 1 & Fritz (2012) \\
\hline Silva (2003) & 1 & Palitot (2007) \\
\hline Ávila et. al (2000) & 1 & Rubenich (2004) \\
\hline Sen $(2000)$ & 1 & Caliari (2002) \\
\hline Kliksberg (1999) & 1 & Passador (2003) \\
\hline Demo (1996) & 1 & Straub (2013) \\
\hline Machado (1994) & 1 & Carmo (2010) \\
\hline Sachs (1986) & 1 & Nascimento $(2005)^{*}$ \\
\hline
\end{tabular}

*Nota: Essa autora iniciou as discussões acerca do tema Desenvolvimento Sustentável, discutido no documento instituído pelo Relatório da Comissão Mundial para o Meio Ambiente e Desenvolvimento (CMMAD) Relatório de Brundtland.

Fontes: BDTD, 2015

Org.: SILVA (2015)

No âmago das discussões relacionadas ao Desenvolvimento e Pedagogia da Alternância, encontrou-se uma diversidade interna deste conceito, que se torna evidente quando se busca adjetivá-lo (Sustentável, Local, Humano, Rural, etc.). Tal fato demonstra a pluralidade de horizontes de análises, e por consequência, causa uma complexidade em termos de fios norteadores teóricos.

Como se pode observar na Tabela 02 , se verificou entre os 20 trabalhos disponíveis de forma completa, uma predominância das ideias de Calvó (1999 e 2002). Esse autor trabalha 
com os aspectos dos CEFFAS baseadas em quatro pilares: a alternância como metodologia, a presença da associação administrativa, a educação integral da pessoa e por último, a ideia de que o Desenvolvimento do meio só é possível se os seus atores sociais obtiverem uma boa formação, daí entra o papel das CEFFAS.

O segundo destaque é para a linha de pensamento baseada em Gimonet (2007). Suas ideias representaram o fio condutor teórico de dois trabalhos, porém, por diversas vezes elas aparecessem como integrante do referencial de outros trabalhos. Trata-se de uma obra de suma importância e que também está relacionada à Pedagogia da Alternância. O autor além de se aprofundar nas questões relativas a esta metodologia, considera também o jovem aluno dos CEFFAS como um ator social e responsável pelas mudanças dentro de seu contexto comunitário. É justamente esse ponto que Gimonet mais foca, ou seja, o fato de que só se alcança um Desenvolvimento satisfatório quando há coerência da teoria com sua realidade.

O terceiro autor abordado, que aparece como condutor de dois trabalhos, é Buarque (1999 e 2002). Para este teórico, o Desenvolvimento é resultado de consideráveis transformações nas bases econômicas e sociais de uma escala de pequenas unidades territoriais e aglomerações humanas. Assim, o autor salienta o que denomina de Desenvolvimento local. Percebe-se que este conceito vai para além das mudanças econômicas, sendo indispensável ultrapassar os dados econômicos quantitativos e alcançar uma melhoria também na qualidade de vida dessa população, o que supõem também, a mudança social.

\section{Considerações Finais}

A problemática de investigação que permeou a construção do presente artigo foi a de estabelecer a relação entre os centros produtores de conhecimento no Brasil, ou seja, os programas de pós-graduação, e as instituições de educação básica e técnica que se utilizam da Pedagogia da Alternância, ou seja, as CFRs e EFAs. Nossa hipótese inicial era de que enquanto a pós-graduação teria uma tendência a se concentrar nos centros urbanos maiores, os CEFFAs estariam localizados em regiões menos desenvolvidas que tem uma participação maior das atividades rurais na composição da economia local. Isso levaria a um distanciamento entre o conhecimento teórico produzido e as práticas efetivas vivenciadas.

$\mathrm{O}$ que se pode perceber numa análise temporal foi que ambos, centros produtores de conhecimento e centros educacionais que se utilizam da Pedagogia da Alternância, tiveram um crescimento gradativo e que nesse processo houve uma aproximação entre estas duas modalidades de instituições. Enquanto os centros educacionais ligados a Pedagogia da 
Alternância mantiveram suas características de localização em áreas mais periféricas, os centros de pós-graduação, embora tenham mantido sua posição de centralidade nas grandes cidades e capitais, passaram a desenvolver paralelamente uma tendência de interiorização, reflexo de uma Política de Desenvolvimento reivindicada pela população de fora dos maiores centros e fomentada pelo Estado.

Esta tendência não se refletiu em um comportamento homogêneo na produção científica sobre a Pedagogia da Alternância nas diferentes regiões brasileiras. Observou-se a manutenção da concentração da produção acadêmica sobre o tema nas regiões Sudeste e Sul, sobretudo nos maiores centros, refletindo o adensamento das instituições mais consolidadas de pós-graduação nestas regiões e o papel destas na formação de quadros para instituições de ensino superior de todas as regiões. A região Nordeste, de outro lado, embora possuísse o maior número de CEFFAS atuantes, foi a que menos produziu discussões acadêmicas sobre a Pedagogia da Alternância, o que evidencia uma maior mobilidade na formação de seus pesquisadores e/ou certo distanciamento dos centros de pós-graduação da região para com este aspecto da realidade.

Por outro lado, sobretudo na última década, evidenciou-se o surgimento de importantes programas de pós-graduação em instituição mais interiorizadas, o que repercutiu numa maior dispersão da produção brasileira de forma geral e também na relacionada à Pedagogia da Alternância. Neste sentido, verificou-se uma aproximação das Políticas Públicas de Desenvolvimento local/regional no que se refere à Educação, seja na esfera dos centros educação básica e técnica que se utilizam dessa pedagogia, seja na esfera dos centros de ensino e pesquisa de pós-graduação. Aí se destaca o papel das universidades regionais na discussão da realidade presente em seu entorno. Todavia, ainda há um forte descompasso entre o número e distribuição dos CEFFAS em relação à produção das discussões acadêmicas acerca deste objeto de estudo.

\section{Referências Bibliográficas}

ABRAMOVAY, R. O capital social dos territórios: repensando o desenvolvimento rural. Revista Economia Aplicada, Ribeirão Preto - SP, v. 4, n. 2, p. 379-397, abril/junho 2000.

AIMFR. Associação Internacional dos Movimentos Familiares de Formação Rural. Disponível em: $<$ http://www.aimfr.org/>. Acesso em 02/11/2015.

ALMADA, F. A. C. de. A experiência educativa de uma Casa Familiar Rural e suas contribuições para o desenvolvimento local. 2005. 114 p. Dissertação (Mestrado em Desenvolvimento Sustentável do Trópico Úmido) - Universidade Federal do Pará, Belém. 2005. 
ALTIERE, M.; MASERA, O.; ALMEIDA, J.; NAVARRO, Z. Reconstruindo a agricultura: ideias e ideais na perspectiva de um desenvolvimento rural sustentável. 2 ed. Porto Alegre: Ed. Universidade-UFRGS, 2009.

AMARAL, S. R. de M. A Escola Família Agrícola e o desenvolvimento comunitário profissional: um estudo avaliativo da EFA de Olivânia em Anchieta no Espírito Santo no período de 1979-2000. 2002. 218 p. Dissertação (Mestrado em Educação) - Universidade de Brasília, Brasília. 2002.

ARAÚJO, S. R. M. de. Escola para o trabalho, escola para a vida: o caso da Escola Família Agrícola de Angical - Bahia. 2005. 221 p. Dissertação (Mestrado em Educação e Contemporaneidade) - Universidade do Estado da Bahia, Salvador. 2005.

ÁVILA, V. F. de et al. Formação educacional em Desenvolvimento Local: relato de estudo em grupo e análise de conceitos. Campo Grande: UCDB, 2000.

BDTD. Biblioteca Digital Brasileira de Teses e Dissertações. Disponível em: < http://bdtd.ibict.br/vufind/>. Acesso em 25/10/2015.

BEGNAMI, J. B. Estudo sobre o funcionamento dos Centros Familiares de Formação por Alternância no Brasil - CEFFAS. Brasília-DF: UNEFAB, 2013.

BORGES, G. S. A formação do protagonismo do jovem rural a partir da Pedagogia da Alternância em Casas Familiares Rurais. 2012. 158 p. Dissertação (Mestrado em Desenvolvimento Regional) - Universidade Tecnológica Federal do Paraná, Pato Branco. 2012.

BRESSIANI, C. M. W. Formação por Alternância e a Sustentabilidade da Agricultura Familiar. 2013. 172 p. Dissertação (Mestrado em Desenvolvimento Regional) Universidade Tecnológica Federal do Paraná, Pato Branco. 2012.

BUARQUE, S. Metodologia de Planejamento do Desenvolvimento Local e Municipal Sustentável. Projeto de Cooperação Técnica INCRA/IICA-PCT, Brasília-DF, 1999.

BUARQUE, S. Construindo o Desenvolvimento Local Sustentável: Metodologia de Planejamento. Rio de Janeiro: Ed. Garamond, 2002.

CALIARI, R. Pedagogia da Alternância e Desenvolvimento Local. 2002. 123 p. Dissertação (Mestrado em Administração)- Universidade Federal de Lavras, Lavras. 2002.

CALVÓ, P. P. Introdução. In: Pedagogia da Alternância - Alternância e Desenvolvimento. Primeiro Seminário Internacional. Salvador: Dupligráfica Editora, 1999.

CALVÓ, P. P. Formação Pessoal e Desenvolvimento Local. In: Pedagogia da Alternância e Desenvolvimento Sustentável. União Nacional das Escolas Famílias Agrícolas do Brasil 12 a 14 de novembro de 2002. p. 126-146.

CARMO, R. M. Qualificação e permanência do agricultor familiar no campo: a Casa Familiar Rural do município de Candói - PR. 2010. 95 p. Dissertação (Mestrado em Desenvolvimento Regional em Agronegócio) - Universidade Estadual do Oeste do Paraná, Toledo. 2010.

CHAVES, A. P. P. Educação e Desenvolvimento Social: uma análise de sua relação em três experiências da pedagogia da alternância. 2004. 2 v., 595 p. Tese (Doutorado em Educação) Universidade Estadual Paulista, Marília. 2004.

DAGNINO, R.; BRANDÃO, F. C.; NOVAES, H. T. Sobre o marco analítico-conceitual da Tecnologia Social. In: DAGNINO, R. (Org.). Tecnologia social: ferramenta para construir outra sociedade. 2. ed. Campinas: Komedi, 2010. p. 71-112.

DEMO, P. Participação é conquista: noções de política social participativa. 3. ed. São Paulo: Cortez, 1996.

ESTEVAM, D. O. Casa Familiar Rural: a formação com base na Pedagogia da Alternância. 2003. 126 p. Dissertação (Mestrado em Administração) - Universidade Federal de Santa Catarina, Florianópolis. 2003. 
ESTEVAM, D. O. Avaliação dos resultados da formação por alternância: um estudo do caso dos egressos da Casa Familiar Rural de Armazém - SC. 2010. 126 p. Tese (Doutorado em Engenharia da Produção). Universidade Federal de Santa Catarina, Florianópolis. 2010.

FONSECA, P. B. C. Ruralidade e escolarização: desafios e propostas educacionais. 2008. 115 p. Dissertação (Mestrado em Educação) - Universidade Federal de Juiz de Fora, Juiz de Fora - MG. 2008.

FRITZ, N. L. Juventude Rural e Sucessão Familiar: O desafio da Pedagogia da Alternância nas Casas Familiares Rurais. 2012. 153 p. Dissertação (Mestrado em Sociologia) Universidade Estadual de Maringá, Maringá - PR. 2012.

GIMONET, J-C. Praticar e Compreender a Pedagogia da Alternância dos CEFFA's. Petrópolis: Vozes, 2007.

GNOATTO, A. A. A Casa Familiar Rural e a Pedagogia da Alternância. 2000. 130 p. Dissertação (Mestrado em Educação) - Universidade Estadual Paulista, Marília. 2000.

JESUS, J. N. As Escolas Família Agrícola no Território goiano: A Pedagogia da Alternância como perspectiva para o Desenvolvimento e o fortalecimento da agricultura camponesa. 2010. 244 p. Dissertação (Mestrado em Geografia) - Universidade Federal de Goiás, Goiânia. 2010.

KLIKSBERG, B. Un tema estratégico: El rol del capital social y la cultura en el proceso de desarrollo. College Park: Latin American Studies Center, 1999. 56 p. (Culture, Democracy and Development, n. 1)

MACHADO, L. R. de S. Mudanças tecnológicas e educação da classe trabalhadora. In: MACHADO et al. (Org.) Trabalho e educação. 2. ed. Campinas: Papirus, 1994, p. 9-23 (Coletânea CBE).

MANHANI, D. C. Uma avaliação do programa de formação de jovens empresários rurais - PROJOVEM. 2000. 118 p. Dissertação (Mestrado em Economia Aplicada) Universidade de São Paulo, Piracicaba. 2000.

MANZONI, J. D. M. Estratégia de transição para o ecodesenvolvimento da agricultura na Ilha dos Marinheiros (Rio Grande - RS): uma abordagem sob a ótica Ignacy Sachs. 2005. 116 p. Dissertação (Mestrado em Educação Ambiental) - Fundação Universidade Federal do Rio Grande, Rio Grande. 2005.

MELO, A. O. Educar para a Sustentabilidade: a experiência da Casa Familiar Rural de Boa Vista do Ramos-Amazonas. 2010. 102 p. Dissertação (Mestrado em Desenvolvimento Regional) - Universidade Federal do Amazonas, Manaus. 2010.

NASCIMENTO, A. L. C. Escolas - Família Agrícola e agroextrativista do estado do Amapá: práticas e significados. 2005. 125 p. Dissertação (Mestrado em Desenvolvimento Sustentável do Trópico Úmido) - Universidade Federal do Pará, Belém. 2005.

NOSELLA, P. Educação no campo: origens da pedagogia da alternância no Brasil. Vitória: EDUFES, 2012.

PALARO, R. Análise sobre a formação para o trabalho na Pedagogia da Alternância na Casa Familiar Rural de Manfrinópolis - PR: possibilidades e limites. 2012. 148 p. Dissertação (Mestrado em Desenvolvimento Regional) - Universidade Tecnológica Federal do Paraná, Pato Branco. 2012.

PALITOT, M. F. S. Pedagogia da Alternância: Estudo exploratório na Escola Rural de Massaroca (ERUM). 2007. 100 p. Dissertação (Mestrado em Extensão Rural). Universidade Federal de Viçosa, Viçosa. 2007.

PASSADOR, C. S. Um estudo do Projeto Escola do Campo - Casa Familiar Rural (19902002) do estado do Paraná: a Pedagogia da Alternância como referencial de permanência. 2003. 176 p. Tese (Doutorado em Educação) -Universidade de São Paulo, São Paulo. 2003. 
RUBENICH, C. J. Avaliação da eficiência da Escola Família Agrícola: COAAMS no desenvolvimento da comunidade rural. 2004. 110 p. Dissertação (Mestrado em Desenvolvimento Local) - Universidade Católica Dom Bosco, Campo Grande. 2004.

SACHS, I. Ecodesenvolvimento: crescer sem destruir. São Paulo: Vértice, 1986.

SANDRI, T. Pedagogia da Alternância e Desenvolvimento Rural: um estudo sobre a Casa Familiar Rural de Reserva - Paraná. 2004. 162 p. Dissertação (Mestrado em Ciências Sociais Aplicadas) - Universidade Estadual de Ponta Grossa, Ponta Grossa. 2004.

SCHNEIDER, C. P. Agricultura familiar e empreendedorismo: Um estudo sobre as trajetórias de jovens egressos do Centro de Desenvolvimento do Jovem Rural (CEDEJOR) no Vale do Rio Pardo/RS. 2008. 194 p. Dissertação (Mestrado em Desenvolvimento Rural) Universidade Federal do Rio Grande do Sul, Porto Alegre. 2008.

SEN, A. K. Desenvolvimento com liberdade. São Paulo: Cia. das Letras, 2000. 409p.

SILVA, L. H. As experiências de formação de jovens do campo: alternância ou alternâncias? Viçosa: UFV, 2003.

STRAUB, P. P. M. A gestão participativa do processo decisório das Casas Familiares Rurais da Região Sudoeste do Paraná: Estudo de Caso nas CFR`s de Pato Branco e Manfrinópolis. 2013. 88 p. Dissertação (Mestrado em Desenvolvimento Regional) Universidade Tecnológica Federal do Paraná, Pato Branco. 2013.

STROPASOLAS, V. L. O mundo rural no horizonte dos jovens. Florianópolis: Editora da UFSC, 2006. 346 p.

TEIXEIRA, E. S.; BERNARTT, M. L.; TRINDADE, G. A.. Estudos sobre Pedagogia da Alternância no Brasil: revisão da literatura e perspectivas para a pesquisa. Revista Educação e Pesquisa. São Paulo, v. 34, n. 2, p. 227-242, mai/ago. 2008.

UNEFAB - União Nacional das Escolas Famílias Agrícolas do Brasil. Distribuição e tipificação das EFAs no espaço territorial brasileiro. Brasília-DF, 2015.

UNEFAB. União Nacional das Escolas Famílias Agrícolas do Brasil. Disponível em: < http://www.unefab.org.br/>. Acesso em 10/11/2015.

VALADÃO, J. A. D. Seguindo Associações Sociotécnicas sob a luz da Teoria do AtorRede: Uma tradução da Pedagogia da Alternância para rotinas e Tecnologias Sociais. 2014. 295 p. Tese (Doutorado em Administração) - Universidade Federal de Pernambuco, Recife. 2014.

WOlOCHEN, M. B. A Casa Familiar Rural e a Pedagogia da Alternância: evidências de desenvolvimento local. 2008, 140 p. Dissertação (Mestrado em Organizações e Desenvolvimento) - Centro Universitário Franciscano do Paraná - UNIFAE, Curitiba. 2008.

Recebido em abril de 2016.

Aceito em maio de 2017. 